\title{
Genetic testing for single gene disorders
}

(Index words: Counselling, ethical aspects, psychosocial problems)

\begin{abstract}
Genetic testing for single gene disorders is becoming available in Sri Lanka. While it offers many benefits, there are concerns about psychological and social problems that can be a consequence of such tests. This article aims to review the potential benefits and disadvantages of genetic testing, and recommends mechanisms that would help minimise problems associated with the inappropriate use of genetic tests.
\end{abstract}

\section{Introduction}

The main clinical outcome of human genetic research has been the ability to offer genetic testing for single gene (Mendelian) disorders. This article is intended to make clinicians aware of important ethical and technical issues involved in genetic testing, and to explain the need for a consensus on such issues.

Genetic testing can be used in the four following situations.

\section{To confirm or refute a clinical diagnosis}

The commonly available tests are for mutations that are easily detected. These include conditions with a single type of mutation (e.g. trinucleotide repeat disorders like Huntington disease [HD]) or where a few common mutations account for a large proportion of affected cases (e.g. cystic fibrosis) [1, 2].

\section{To identify carriers}

Carriers are mostly unaffected by the disease but are at a risk of having affected children. When both parents are carriers of an autosomal recessive disease, there is a $25 \%$ risk of having an affected child. In Xlinked recessive disease, the son of a female carrier has a $50 \%$ risk of being affected. Carriers can be identified within affected families when the request for carrier testing is usually initiated by the at risk person. Population screening (e.g. for thalassaemia carriers) is offered by doctors to individuals with little or no experience of the disease.

\section{For presymptomatic (predictive) diagnosis}

This is available for late onset conditions including untreatable neurodegenerative diseases (e.g. HD, which has an onset usually after reproductive decisions are made) [3] or the familial cancer syndromes (e.g. BRCA1 gene mutation linked with breast and ovarian cancer).

\section{For prenatal diagnosis (PND)}

Prenatal diagnosis can only be offered if the causative gene mutation is known. PND is performed using chorionic villus sampling (around 10 to 12 weeks) or amniocentesis (16 to 18 weeks). If prevention or treatment is not available, one option is termination of an affected pregnancy. Termination of pregnancy for foetal anomalies is illegal in Sri Lanka.

The diagnosis of a genetic disease has implications for the individual concerned as well as other family members. For example, a cerebellar infarction is devastating for the affected person but diagnosing an autosomal dominant spino-cerebellar ataxia is worse, as siblings and children are also at a risk of developing it later [2].

In some single gene diseases, routine testing will not detect all the causative mutations. For example, in Duchenne muscular dystrophy (DMD), specific, intragenic deletions in the dystrophin gene occur in about $60 \%$ of cases $[1,2]$. A negative result after screening for deletions may indicate that a different type of mutation is present or that the child does not have DMD. The identification of DMD carriers can be difficult, even when a causative mutation is found in an affected male in the family $[1,2]$.

In the triplet repeat disorders, care has to be taken to differentiate between unaffected individuals with a premutation (as in fragile $\mathrm{X}$ syndrome) from those with the full mutation $[1,2]$. In some cases, the expansion falls in a grey area, and interpretation of the test requires caution $[1,2]$. When mutation detection is restricted to screening for common ones, the residual risk has to be explained to the tested individual. A negative test result will reduce the risk but not altogether eliminate it $[1,2]$.

Genetic testing in a family with cancer syndromes can identify people at high risk of cancer to offer screening or preventive therapy. Mutation detection rates are low with about $60 \%$ of breast cancer families having an identified mutation [1]. The presence of a mutation in one of the breast or colon cancer predisposing genes signifies an increased risk but not inevitability of a cancer, or its tissue of origin (e.g. BRCA1 mutations are associated with a risk of carcinoma in different epithelial tissues) [4]. Family members tested negative may still develop a sporadic cancer.

\section{Psychological problems following genetic testing}

There is evidence of adverse psychological effects of genetic tests, especially if the individual is not adequately informed of its repercussions [5-7]. Generating an unpleasant result without the individual or family's informed consent can cause distress. As the main implications of the information generated are for the individual and his family, the right "not to know" has to be respected, especially when diagnosing untreatable disorders. 
Predictive testing for late onset diseases enables clarification of risk before making career or reproductive choices. There is concern about the psychological consequences of a healthy person being informed of a positive predictive test result. In predictive testing for HD, psychological problems have been observed even in people found not to have the mutation [8]. In families undergoing mutation testing for colorectal cancer predisposition, the absence of a detectable mutation has resulted in reduced compliance with screening, indicating a false belief that the test was negative [9]. Experience with other tests show that individuals found not to be carriers can also have adverse effects including a sense of invulnerability or false optimism about their health [10].

\section{Risk of stigmatisation}

This may happen at the level of the family, community or institutions [11]. One thalassaemia carrier testing program [12] caused stigmatisation of carriers, who were unable to marry anyone else except other carriers! In countries where life and health insurance are widely availed, there are problems in obtaining insurance for people with a family history of genetic disease. In this country, utilisation of insurance is less widespread, and many who are able to afford genetic testing are also likely to be able to have life or health insurance. Insurance companies or potential employers should not be allowed to encourage or demand genetic testing as a condition for obtaining insurance or employment, in keeping with acceptable practices in the developed world [13, 14]. Discrimination can also occur within a health care system. The birth of a child with a genetic disease has repercussions for society, but the people who are most affected by the financial, social and psychological burden are the parents. Parents, who take a calculated risk, do so because of a compelling wish to have a child. China has laws preventing people with a genetic disease or at risk of having affected children from reproducing [15], but such coercive laws may be less acceptable elsewhere in Asia.

\section{Testing children}

Testing children for adult onset genetic disorders has been widely discussed, and the consensus is that it should not be allowed until the individual is able to give informed consent [16-18]. Carrier testing may generate results which are misunderstood or forgotten at the time the person is embarking on parenthood. It is better deferred until adulthood [19].

\section{Issue of confidentiality of genetic information}

Family histories, results of genetic tests and stored genetic material need to be protected to ensure confidentiality [11]. In some countries genetic data is usually only divulged to other parties (including other family members, doctors, employers, insurers or the police) with consent. Acceptable ethical practice in the west suggests that informed consent should be obtained before submitting stored genetic materials for investigations other than the ones for which it was obtained [20, 21]. It may be desirable to destroy samples following the test or after an agreed time.

\section{Genetic counselling}

Genetic counselling involves giving information to people that enables them to make an informed choice from the options available [22]. It is intended to be nondirective, especially with regard to reproductive decisions. Given the evidence from other countries about incorrect understanding and adverse psycho-social consequences in the absence of adequate information, it seems justified to offer counselling before genetic testing. Data regarding the level of understanding and the acceptability of nondirective couselling should be collected to plan future genetic services.

Before diagnostic genetic testing, counselling would involve a discussion about the disease, its mode of inheritance and the significance of a negative or positive test result [22]. The guidelines to confirm a clinical diagnosis of HD stipulate a signed consent before laboratory testing [23]. Less stringent guidelines apply to other diseases, but similar discussions are usually offered to the affected person or family. In presymptomatic testing for HD, there are widely accepted guidelines about counselling before and after the test, given the potential significance of a positive result [23,24]. Similar guidelines are available for presymptomatic testing for cancer syndromes [25].

Problems with carrier testing include confusion about the significance of being a carrier [5, 26], stigmatisation [6,12] and psychological problems [5-7]. Most carrier testing programs include some form of information to enable informed decision making [27]. If no treatment is available to prevent or ameliorate a disease, one option for carriers is to undergo prenatal diagnosis and termination of affected pregnancies. As this is not an option currently available in Sri Lanka, should carrier testing be offered? Counselling will help individuals to decide on the issue: some may wish to find out their carrier status and make reproductive choices; others may wish to exercise their right not to know.

\section{Conclusions}

Genetic testing is available in Sri Lanka but evidence from other countries suggests that genetic tests can have adverse consequences. Informed decision making by people will circumvent some of these problems and there should be consensus on and adherence to guidelines regarding genetic testing. Genetic testing of children for 
adult onset disorders and carrier testing for X-linked or recessive diseases should be discouraged. The psychosocial outcomes of genetic testing and the demand for termination of pregnancies affected with severe genetic diseases should be investigated. If termination is widely requested, lobbying for a change in the abortion law may be justified.

\section{References}

1. Gene Clinics. http://www.geneclinics.org

2. On line Mendelian inheritance in man. http://www.ncbi.nlm.nih.gov/omim

3. Evers-Kiebooms G, Nys K, Harper P, Zoeteweij M, Durr A, et al. Predictive DNA-testing for Huntington's disease and reproductive decision making: a European collaborative study. European Journal of Human Genetics. 2002; 10: 167-76.

4. Ford D, Easton DF, Bishop DT, Narod SA, Goldgar DE. Risks of cancer in BRCA1-mutation carriers. Breast Cancer Linkage Consortium. Lancet 1994; 343: 692-5.

5. Axworthy D, Brock DJ, Bobrow M, Marteau TM. Psychological impact of population-based carrier testing for cystic fibrosis: 3-year follow-up. UK Cystic Fibrosis Follow-up Study Group. Lancet 1996; 347: 1443-6.

6. Evers-Kiebooms G, Denayer L, Welkenhuysen M, Cassiman J-J, van den Berghe H. A stigmatizing effect of the carrier status for cystic fibrosis? Clinical Genetics 1994; 46: 336-43.

7. Marteau TM, van Duijn M, Ellis I. Effects of genetic screening on perceptions of health. Journal of Medical Genetics 1992; 49: 24-6.

8. Goizet C, Lesca G, Durr A. French group for presymptomatic testing in neurodegenerative disorders. Neurology 2002; 59: 1330-6.

9. Johnson KA, Trimbath JD, Petersen GM, Griffin CA, Giardiello FM. Impact of genetic counselling and testing on colorectal cancer screening behaviour. Genetic Testing 2002; 6: 303-6.

10. Weinstein ND. Why it won't happen to me: perceptions of risk factors and susceptibility. Health Psychology 1984; 3: $431-57$.

11. World Health organization. Genomics and World Healthreport of the advisory committee on health research. WHO: Geneva, 2002: 155-60.

12. Stamatoyannopoulos G. Problems of screening and counselling in the haemoglobinopathies. In: Motulsky AG, Ebling FLB, eds. Birth Defects. Proceedings of the fourth international conference, September 2-8, 1973, Amsterdam. Amsterdam: Excerpta Medica, 1974.
13. Watson M, Greene C. Points to consider in preventing unfair discrimination based on genetic disease risk: a position statement of the American college of medical genetics. http://www.acmg.net/resources/policies.

14. Harper P. Insurance and genetic testing. Lancet 1993; 267: 2503-8.

15. Western eyes on China's eugenics law. Lancet 1995; 346: 131.

16. Harper P, Clarke A. Should we test children for adult genetic disease? Lancet 1990; 335: 1205-6.

17. Dalby S. Genetics interest group response to the UK Clinical Genetics Society report 'The genetic testing of children'. Lancet 1995; 32: 490-1.

18. Clayton EW. Removing the shadow of the law regarding the debate about genetic testing of children. American Journal of Medical Genetics 1995; 57: 630-4.

19. Clarke A. The genetic testing of children. In Harper P, Clarke A, eds. Genetics, Society and Clinical Practice. 1st edn. Oxford: BIOS scientific publishers, 1997: 15-29.

20. American college of medical genetics. Standards and guidelines for clinical genetics laboratories. http:// www.acmg.net/Pages/ACMG_Activities/stds.2002/g.htm

21. UK advisory committee on genetic testing. Advice to research ethics committees: points to consider in ethical review of medical research involving genetic testing. http://www.doh.gov.uk/genetics/recrev3.htm

22. Harper P. Genetic Counselling-An Introduction. Practical Genetic Counselling. 4th edn. Oxford: ButterworthHeinemann, 1993.

23. Tyler A, Crauford D. Presymptomatic testing for Huntington disease in the UK. British Medical Journal 1992; 304: 1592-6.

24. World federation of neurology research group on Huntington disease: a worldwide survey. Journal of Medical Genetics 1993; 161: 481-8.

25. Decruyenaere M, Evers-Kiebooms G, Denayer L, Welkenhuysen M, Claes E, Legius E, Demyttenaer K. Predictive testing for hereditary breast and ovarian cancer: a psychological framework for pre-test counselling. European Journal of Human Genetics 2000; 8: 130-6.

26. Loader S, Sutera CJ, Segelman SG, Kozyra A, Rowley PT. Prenatal hemoglobinopathy screening. IV. Followup of women at risk for a child with a clinically significant hemoglobinopathy. American Journal of Human Genetics 1991; 49: 1292-9.

27. Genetic screening: ethical issues. http://www.nuffieldbioethics.org/genetic screening.

Deepthi de Silva, Senior Lecturer, Department of Physiology, Faculty of Medicine, University of Kelaniya, Ragama, Sri Lanka. Tel: +94 1 2958037, e-mail: deepthidesilva@lycos.com (Competing interests: none declared). Received 2 June 2003 and revised version accepted 8 October 2003. 